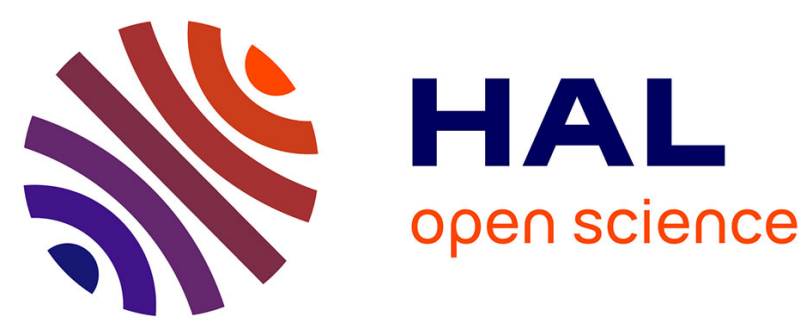

\title{
How teachers prepare for the unexpected: bright spots and breakdowns in enacting pedagogical plans in class
}

Ghita Jalal, Valentin Lachand, Aurélien Tabard, Christine Michel

\section{To cite this version:}

Ghita Jalal, Valentin Lachand, Aurélien Tabard, Christine Michel. How teachers prepare for the unexpected: bright spots and breakdowns in enacting pedagogical plans in class. 13th European Conference on Technology Enhanced Learning (EC-TEL 2018), Sep 2018, Leeds, United Kingdom. pp.59 - 73, 10.1007/978-3-319-98572-5_5. hal-01833057

\section{HAL Id: hal-01833057 https://hal.science/hal-01833057}

Submitted on 2 Oct 2018

HAL is a multi-disciplinary open access archive for the deposit and dissemination of scientific research documents, whether they are published or not. The documents may come from teaching and research institutions in France or abroad, or from public or private research centers.
L'archive ouverte pluridisciplinaire HAL, est destinée au dépôt et à la diffusion de documents scientifiques de niveau recherche, publiés ou non, émanant des établissements d'enseignement et de recherche français ou étrangers, des laboratoires publics ou privés. 


\title{
How teachers prepare for the unexpected Bright spots and breakdowns in enacting pedagogical plans in class
}

\author{
Ghita Jalal $^{1}$, Valentin Lachand ${ }^{1}$, Aurélien Tabard ${ }^{2}$, and Christine Michel ${ }^{1}$ \\ 1 Univ Lyon, INSA-Lyon, CNRS, LIRIS, UMR5205, F-69621, LYON, France \\ \{ghita.jalal, valentin.lachand, christine.michel\}@liris.cnrs.fr \\ 2 Univ Lyon, Université Lyon 1, CNRS, LIRIS, UMR5205, F-69621, LYON, France \\ atabard@liris.cnrs.fr
}

\begin{abstract}
When teachers plan pedagogical activities, they define the pedagogical strategies, resources, and tools they will use. But, as they run these activities in class, they have to adjust their plans, according to available resources, and to live breakdowns. Teachers have very little time to adjust their plans in class, and existing tools offer very little support for live changes. We conducted contextual interviews with eight middle and high school teachers to better understand their practices in planning and enacting pedagogical activities. We identify a set of breakdowns in conducting their activities, and the strategies teachers develop to cope with them. Teachers use digital tools to keep a trace of their plans and to improve their enactment strategies. They design plans students can enact directly, or define the content, the structure, or both, with students in class. Most enactment issues are software and hardware breakdowns. Based on our findings, we propose implications for the design of novel tools to support teachers in enacting their plans in class. These tools should capture traces of the activity as it happens. They should support externalizing plans, and sharing them with students. Ultimately, planning and enactment tools should support richer cross-device interactions.
\end{abstract}

Keywords: Interviews, qualitative study, teacher practices, planning, teaching tools

\section{Introduction}

Pedagogical plans are externalizations of learning activities as teachers anticipate them. As they enact these plans during the session, teachers refine, adapt and reflect on them on the go. Sharples [20] describes the complexity of the teacher's role: "not only [s/he] has to prepare lesson plans, accommodate formal curricula, and follow regulations on health, safety and discipline, but also understand and manage a variety of technologies such as interactive whiteboards, desktop and laptop computers."

As they plan learning activities, teachers know their plans are likely to change as the activity unfolds. Yet, they need to prepare the structure and content they 
intend to include in the session. As they enact their plans in class, teachers know more about the activity. They can refine their plans, or adjust them depending on the situation. Yet, teachers often make these changes in a few seconds or minutes, while running the session at the same time. This is especially challenging when taking into account the pedagogical and technical constraints teachers manage at the same time when they run their sessions [8].

There is a tension between planning and enacting pedagogical activities [4]. As a result, teachers need to switch between routines and improvisations. Routines are practices they developed over the years. Improvisations are quick fixes they put in place, during the session, to respond to events they did not expect in their plans [15]. After class, teachers have more time to revisit their plans, edit them, rethink their routines, and evaluate their improvisations. Yet, they do not have access to context elements they experienced first-hand, during the session.

In this paper, we investigate the gap between the plans teachers create, and how they enact them in class. Our end goal is to propose interactive tools that support teachers in enacting and adapting their plans in class. We conducted contextual interviews with middle and high school teachers. We report on their routines and practices as they plan and enact pedagogical activities. We focus on breakdowns and bright spots in enacting teacher plans, and propose design recommendations to create tools to support teachers in the transition from planning to enactment.

\section{Related work}

Scripting [23] and Orchestration [5] provide descriptive and generative guidelines to design tools that support teachers in planning and enacting their plans in class. We discuss how teachers use existing tools, the limitations of these tools, and how paradigms such as scripting and orchestration can help us understand teachers' practices in planning and enacting pedagogical activities in class.

\subsection{Plans and action in social sciences}

Plans and action have long been used in sociology to describe and formalize the tension between how plans condition and define action. Akrich [1] compared plans to interaction "scripts" or "scenarios" that await for actors to enact them, and transform them into technical objects [1]. Suchman's work on situated action emphasized how plans are not enough to ensure successful interaction: plans unfold as "ad-hoc responses to the actions of others and to the contingencies of particular situations" [22]. Streibel discussed and interpreted plans and situated action in learning [21]. Instructional plans determine the cognitive model of human learning, but cannot control situated learning [21]. These theories describe how plans and action interplay in users' practices. While plans condition action, they do not determine how it unfolds.

We use these theories to frame our empirical findings, while focusing on what field observations can teach us about the design of novel interactive tools to support teachers' transition from plans to action. 


\subsection{Plans in pedagogical situations}

In educational settings, Dore describes teachers' plans and pedagogical strategies as "techniques and means used to reach [an] educational goal" [10]. Several models describe pedagogical plans. The narrative model $[10,16]$ structures pedagogical plans at three levels: courses, activities and steps. A learning scenario describes course elements. These include domain knowledge, curriculum, aimed age, school level, and learning goals. It also describes elements more specific to each activity. These include required skills, teacher and student tools, phases, and assessment.

Models such as LOM (Learning Object Metadata), SCORM (Sharable Content Object Reference Model) or IMS-LD (Instructional Management SystemsLearning Design) [16] base their structure on these principles. These models describe pedagogical objectives and individual learning activities. Yet, they grow in complexity when describing collaborative activities where students' and teachers' roles are dynamic. Also, these pedagogical models do not account for the changes in pedagogical plans, and the challenges teachers face in enacting them in class.

Scripting is another approach to define plans for collaborative activities. It focuses on the way students collaborate [7]. CSCL scripts define more precisely how group members interact to solve a problem. There are two levels of scripts: micro-scripts and macro-scripts [6]. Micro-scripts are models students need to internalize (local perspective), such as argumentation or dialogue models whereas macro-scripts are pedagogical models (global perspective). One of the main differences between micro-scripts and macro-scripts is duration. Micro-scripts are short-termed and students need to internalize them. Macro-script cover longer periods and are directly linked to pedagogical objectives.

Kobbe [14] identifies the following script components: activity participants, groups and roles assigned to group members (roles are "associated with privileges, obligations and expectations"), and activities. In this model, scripts structure pedagogical activities and learners' resources. For Dillenbourg and Hong [6], script components are: activity type, sequencing in time, participants' roles, distribution and activity representation. This model mostly adds pedagogical objectives to Kobbe's model.

Scripts describe plans teachers design to anticipate the dynamics of collaborative activities. Learning design provides a broader perspective on planning. The term design here refers to: "the process of mapping and/or actually developing specific resources for teaching or learning" [13].

\subsection{Plans in practice}

Few empirical studies focus on how teachers use theoretical models in practice, to script real pedagogical activities. Dore et al. found that the narrative reference model can guide training to clarify a teaching frame for students. But, they still need assistance for novel forms of training at school or outside [10]. Rodríguez-Triana et al. [17] conducted two studies of an implementation of a 
model combining learning design (scripting) and learning analytics (conducting). They found that designing scripts with monitoring information helps the teacher anticipate what can happen in class during the scripting phase.

\subsection{Conducting pedagogical activities}

Research on learning has explored planning and conducting pedagogical activities since its inception. In particular, the orchestration metaphor has been increasingly used to describe the "live" management of unfolding activities in the classroom [7]. Work on orchestration proposes principles to structure a training timeline (or graph) to support teachers in conducting educational activities. This structure takes into account a number of practical constraints (length, curriculum, number of students, etc.) [5] and ways to improve activity progress (continuity, awareness, relevance, etc.) [8].

Primo-scripting is an orchestration phase where the teacher identifies constraints and pedagogical objectives [23]. In primo-scripting, teachers create a scenario with available resources and strategies to implement this scenario in the classroom. Run-time scripting is an orchestration phase where teachers edit scripts live. It helps them reconsider their activity's structure, implementation and teaching objectives [23]. Orchestration becomes challenging when there is a division between learning at school and outside [9] (e.g., homework). Sharples et al. proposed shared orchestration $[19,11,20]$ as a new way of conducting activities where teachers and learners can orchestrate their own activities.

Orchestration tools support enacting pedagogical activities in class $[8,9,18]$. Live monitoring dashboards give teachers feedback about learners' progress in multi-device contexts [15], but at the cost of extra mental workload [20]. Tangible devices create ambient awareness for teachers [9]. For example, Lantern [8], an orchestration lamp, changes color to inform teaching assistants about students' progress in problem solving sessions.

\subsection{Transitioning from scripting to orchestration}

Scripting tools support creating plans before class, while orchestration tools support enacting these plans in class. Yet, scripting and orchestration do not support the transition from planning to enacting plans in class. To our knowledge, teachers have little to no technical support in managing this transition. Orchestration literature also rarely discusses what happens after class. Orchestration systems do not focus nor support teachers' post-session reflections to adapt and reuse their plans for future sessions. We focus on how teachers currently manage this transition as they prepare and run learning activities. We follow a methodology similar to [24], to investigate teachers practices with and without digital tools. In the following we present results of contextual interviews with teachers, and highlight bright spots and breakdowns in their attempts to enact their plans. 


\section{Study}

We conducted contextual interviews to better understand the interplay between digital tools and teachers' practices in planning and enacting pedagogical activities. We focused on moments where pedagogical plans did not proceed as intended and on how teachers dealt with these situations.

\subsection{Participants and procedure}

We interviewed eight French middle and high school teachers (3 women, 5 men; age 26-50; 5 in middle school, 3 in high school) about their practices in planning and enacting pedagogical activities. Teaching topics include French literature, Physics, Chemistry, History, English, German, Biology and Computer Science.
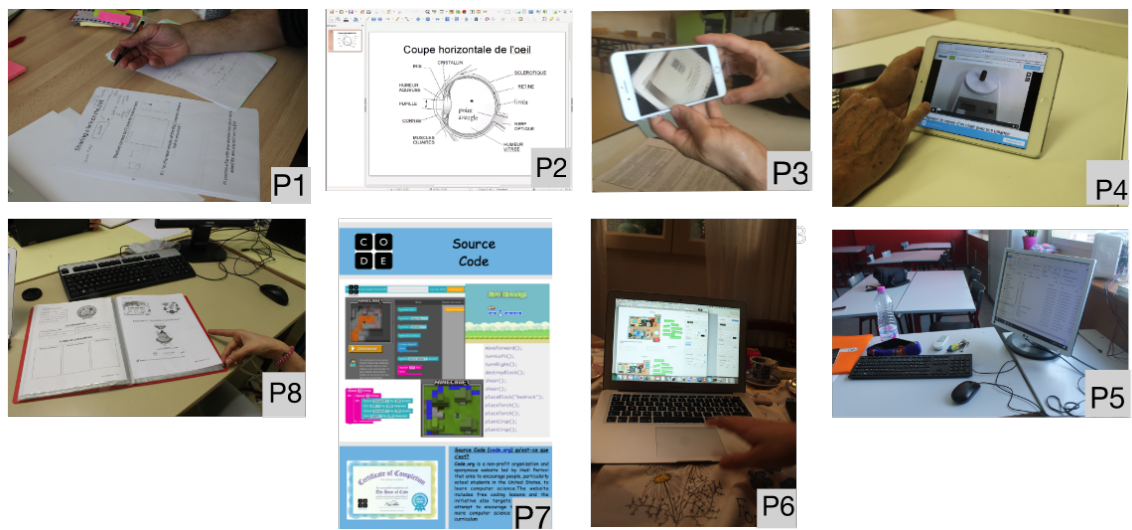

Fig. 1: During the interviews, teachers showed us how they created their plans, and described how they used them to enact the session.

We conducted semi-structured interviews with participants in their classroom or office for about one hour. We asked participants to walk us through the planning and enactment steps of a specific teaching session. We also asked them to show us the documents they created before, during and after the session. We probed for situations where planning or enacting was particularly effective, but also when it was extremely difficult.

\subsection{Data Collection and analysis}

We recorded audio for each interview and took written notes. We also recorded videos of participants' interactions with the documents they had created, and photographed relevant elements of their classroom settings (position of student tables, interactive board, tablets, routers). We transcribed the eight interviews, and extracted examples of pedagogical moments -stories- where teachers enacted 
plans they created before the session. We used thematic analysis [2] to extract themes that describe how teachers plan and enact pedagogical activities. We considered how teachers plan their sessions before class, and how they use these plans as they enact their session with students. We also identified main types of breakdowns teachers reported as they attempted to enact their plans in class, and the tools (digital or physical) they used to plan and run the activity. We created a visual representation of each story [12] to validate it, and to gather more contextual information in a second meeting with the participant.

In the following, we present and discuss how teachers use current tools to plan and enact pedagogical activities in real classroom situations.

\section{Results}

We extracted 48 stories in total (between 2 and 11 stories by participant). Each teacher in our interview walked us through a session they recently run with their students. These narrative descriptions of teachers' actions to prepare and run pedagogical activities helped us identify several activity structures All participants alternated group and individual activities in their sessions.

In the following, we report on how teachers in our interviews planned their sessions, and how they enacted them in class. We focus on the tools they used, and on the breakdowns and bright spots in their enactment strategies.

\subsection{How do teachers plan a pedagogical activity?}

All participants planned their sessions before class. Teachers in our interviews used different names to describe the pedagogical plans they created. P2, a physics teacher, called the plan: "a connecting thread", and a "contract" between him and students. P3, a history teacher, talked about a "work plan", referring to the technique he used to construct pedagogical activities [3].

Table 1: Types of tools used to run pedagogical activities in class (percentages)

\begin{tabular}{|c|c|c|c|c|c|c|c|c|}
\hline \multirow{2}{*}{ Planning too } & \multicolumn{4}{|c|}{ Teacher tool } & \multicolumn{4}{|c|}{ Student tool } \\
\hline & No tool & Digital & Physical & Total & No tool & Digital & Physical & Total \\
\hline No & 1.9 & 1.3 & 9.4 & 22.6 & 0.0 & 13.2 & 9.4 & 22.6 \\
\hline Digit & 26.4 & 35.8 & 11.3 & 73.6 & 0.0 & 41.5 & 32.1 & 73.6 \\
\hline Physical & 1.9 & 0.0 & 1.9 & 3.8 & 0.0 & 0.0 & 3.8 & 3.8 \\
\hline
\end{tabular}

Teachers used digital tools to plan their sessions in almost $3 / 4$ of the situations they described, whether they used digital tools to conduct the activity in class $(35.8 \%)$ or not $(26.4 \%+11.3 \%)$. They also created digital plans in sessions where they did not assign students to use digital tools (32.1\%).

In about a third of the stories (35.8\%), teachers created a plan directly in a digital tool, and later used the same tool to conduct their session. For example, $\mathrm{P} 5$, an English teacher, planned a session in $\mathrm{h} 5 \mathrm{p}^{3}$, an online teaching tool for

\footnotetext{
${ }^{3}$ www.h5p.org
} 
creating interactive content. P5 and her students both used the same tool to run the activity in class.

Students could follow the teacher's plan autonomously in around $1 / 4$ of the stories. In these cases, teachers let students run the plan, and provided feedback as needed. Some teachers (32.1\%) also created digital plans, and printed them for students to use in class. Teachers used these digital versions to keep a trace of the session progress for future years. For some courses (22.6\%), teachers did not create representations of their plans before the session (table 1). In these cases, teachers had in mind the structure they would follow. They established routines they followed in several sessions. Both teachers and students were aware of these routines. For example, $\mathrm{P} 4$, a physics teacher, always starts with questions, follows with a short experiment, and another series of questions. The session structure in this case is implicit. $\mathrm{P} 4$ does not create a representation of the plan before class, but he and the students know how the session will proceed.

Our results suggest that teachers often create representations of their plans ahead of time. Digital plans helped teachers integrate the session structure and student activity in the same tool. Few digital plans could be run autonomously by the students.

\subsection{What goes in teacher plans?}

The teachers we interviewed left parts of their plans open, and defined them in class, as the activity unfolded. We found that preparation could be organized around the structure of the activity or its content.

Planning content first, and defining structure in class: More than half participants (five out of eight), prepared or created content before class, only to decide in class on how they would present it to students. For example, P5, an English language teacher, used a Web application, Genially, to add dynamic links to a painting. In class, she decided of the order in which she opened and presented the links based on her discussion with students.

Teachers prepare the content, and use it to guide the discussion, depending on their interaction with students in class. Two participants provided examples where they prepared several versions of the content. In class, they decided which version to use depending on how the session unfolded. P4, a physics teacher, created many versions of the same activity, with different levels of difficulty. He started with a less detailed version, and provided more details as he perceived students struggling.

Planning structure first, and defining content in class: Half participants (four out of eight) represented the session's structure in their plans, and then created the content with students, in class. For instance, P5, an English language teacher, came to class knowing the structure, but created the content in class, with students. She created a mind map, before class. Then, in class, she filled in the content with students: "I wanted to know the vocabulary they already know." 
(P5) One participant created both the structure and content before class. Only to re-create the content with students in class. As she explained: "I was cheating, I led them where I wanted them to go" (P8).

Teachers set constraints in the planning phase. They do not create fully detailed plans. At the same time, they do not leave the session totally open. They keep a level of freedom for them to adjust the plan according to what happens in class.

\subsection{Enactment bright spots and breakdowns}

During the interviews, all eight teachers presented a version of their plan for the session we discussed. They used the plan in class with students. P1, a French literature teacher, writes the plan on the blackboard before the session begins, and presents it to students to start the session. Participants often used a printed version of the plan, or a digital version on a mobile device, such as a tablet. In some cases, they also had versions of the plan on a static computer in the classroom (fig. 2).
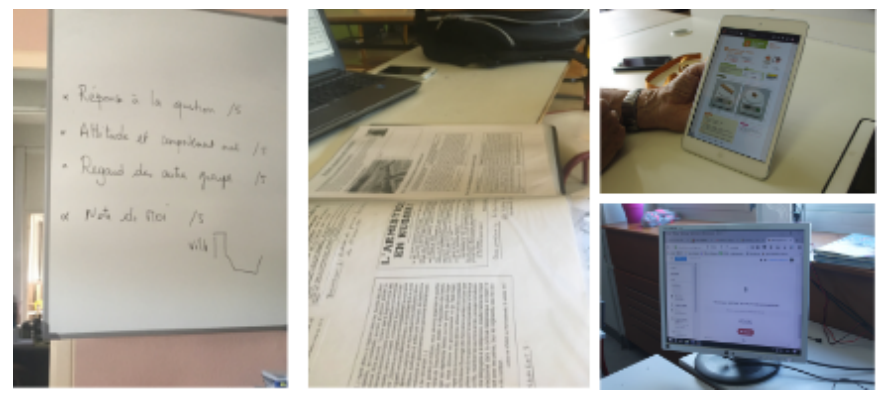

Fig. 2: Teachers externalized their plans on different media. They showed us plans on the physical board, on paper, on a digital tablet, or on the classroom's computer.

Half our participants presented pedagogical situations where they changed their plans in class. New content, structure, or live events lead them to change the plan they initially anticipated. Teachers make room for changes in their plans, and attempt to work around live breakdowns to reach their pedagogical objectives.

To understand if planning helped teachers succeed in conducting their session, we extracted satisfaction statements from participants' stories about the session they described and mapped these statements to the tools they used to plan this specific session (table 2). Bright spots and breakdowns in participant stories are time, space and resources issues:

- Time issues are about the expected versus the actual time it took the teacher to run the session. 
- Physicality issues [5] include situations where teachers needed to be mobile in the classroom.

- Resource issues are about content transfer and distribution. For example, these issues include accessing plans the teachers created at home on the school computer, managing software versions, and distributing content on several devices.

Table 2: Teachers' satisfaction of their enactment strategies by plan type (Percentages)

\begin{tabular}{|c|c|c|c|c|c|c|}
\hline \multirow{2}{*}{ Plan type } & \multicolumn{2}{|c|}{ resources } & \multicolumn{2}{|c|}{ time } & \multicolumn{2}{|c|}{ space } \\
\hline & $(-)$ & $(+)$ & $(-)$ & $(+)$ & $(-)$ & $(+$ \\
\hline & 3,8 & 18.9 & 5.7 & 17.0 & 1.9 & \\
\hline & 18.9 & $\mid 54.7$ & 20.8 & 52.8 & 3.8 & \\
\hline & & 3.8 & 0 & 3.8 & 0 & \\
\hline Total & 22.6 & 77.4 & 26.4 & 73.6 & 5.7 & \\
\hline
\end{tabular}

To understand if teachers managed to run their session with the tools they planned to use, we identified stories where breakdowns occurred and mapped them to the tools teachers and students used during the session(table 3 ).

Enactment bright spots In most stories (more than 70\%), teachers were satisfied with their enactment strategies. They were satisfied of their strategies in managing resources $(77.4 \%)$, time $(73.5 \%)$, and space $(94.3 \%)$ (table 2 ).

In many cases (more than 50\%), interviewees chose to plan their sessions with digital tools (table 2). Teachers did not articulate their involvement during the session explicitly in the interviews. Yet, their plans reflected different levels of involvement in the activity in class. In most stories, teachers closely monitored the activity in class.

Teachers in our interviews gave various examples of routine plans they reused to conduct several pedagogical activities. They created digital plans to keep a trace of their practices, and to improve their enactment strategies over time. Teachers also created detailed digital plans for students to run independently. "I prefer this type of activities because students can finish them at home." (P5). Other teachers used this strategy to have more time in class to answer students' questions. For example, P5 created an interactive video for students using $E d$ puzzle, a teaching web application for interactive videos. Using this tool, she could see, in class, sections of the video students viewed the most. P5 adjusted her plan to spend more time on these problematic sections. Other teachers created detailed plans to make sure they covered all educational objectives for the session. P2, a physics teacher, created a plan to guide him through the session. He created a checklist with important points to search for in students' answers to his questions in class. He used a printed version of the checklist during the session. 
Table 3: Breakdowns and Bright Spots by tool type (Percentages)

\begin{tabular}{l|l|r|r|r} 
& \multicolumn{2}{|c|}{ Teacher tool } & Student tool & Digital \\
\hline \multirow{3}{*}{ Breakdowns } & Physical & Total \\
\hline \multirow{3}{*}{ Bright Spots } & No tools & 3.8 & 3.8 & 7.5 \\
& Digital & 35.8 & 1.9 & 37.7 \\
& Physical & 0.0 & 9.4 & 9.4 \\
& Sub-total & $\mathbf{3 9 . 6}$ & $\mathbf{1 5 . 1}$ & $\mathbf{5 4 . 7}$ \\
\hline \multirow{3}{*}{} & No tools & 5.7 & 17.0 & 22.6 \\
& Digital & 9.4 & 0.0 & 9.4 \\
& Physical & 0.0 & 13.2 & 13.2 \\
& Sub-total & $\mathbf{1 5 . 1}$ & $\mathbf{3 0 . 2}$ & $\mathbf{4 5 . 3}$
\end{tabular}

In other cases, the plan was limited or intentionally open for the teacher to add explanations, details, or examples. Teachers gave instructions live, and recreated the content with students in class. Their goal was to maintain interaction and student involvement during the session. For example, P8, a biology teacher, provided students with a "session plan", with the structure of the activities they will run in class. Students filled in the plan with answers to P8 questions during the session. Then, P8 copied the answers in class, and uploaded a version of the "session plan" to the school's digital system.

Enacting teacher plans in class requires them to take into account potential breakdowns. They should be able to adjust their plans live, to use alternative tools, and to change instructions and content depending on unexpected events during the session.

Breakdowns in enacting pedagogical plans: Interviews with teachers revealed different types of breakdowns in enacting plans they created before class (table 4). Most breakdowns in enacting the session are related to time $(26,4 \%)$ and resources $(22,6 \%)$ (table 2). In more than half of the stories (54.7\%), teachers did not manage to run their sessions as intended (table 3). Breakdowns were more frequent $(35.8 \%)$ when teachers planned and run the session with digital tools (table 3 ).

Content and instruction breakdowns are cases where teacher plans did not correctly respond to unexpected live events in class. We found examples of pedagogical moments where teachers changed instructions and content live, based on students' feedback in class. For example, P3 a history teacher, assigned a group to work on writing a biography. As they started, P3 realized that students were writing a full textual biography. He adjusted the instructions to ask for the birth and death dates, and for major events in the life of the character. Similarly, P5, an English teacher, created an activity around a Martin Luther King video. Although she designed the activity for students to regulate on their own, she stopped in class after each video section: "This video content is too difficult, I want to explain the words as we go" (P5).

More than half participants (six out of eight), provided examples of hardware breakdowns. In these cases, teachers' plans broke when they moved them across 
Table 4: Number of stories and participants per breakdown type

\begin{tabular}{|c|c|c|}
\hline Breakdowns & Stories & Participants \\
\hline Software & 16 & \\
\hline Hardware and Network & 10 & \\
\hline Content and Instructions & 3 & 2 \\
\hline
\end{tabular}

different devices. They are also linked to content access from different locations, and from different devices. For example, P2, a physics teacher, replicated his plans on dropbox, and on a USB stick, to avoid loosing them when moving them out of the classroom computer. Several teachers also reported on hardware breakdowns related to sharing hardware among students or student groups. For example, P1, a French literature teacher, used a personal tablet for an activity where student groups created a movie. In class, P1 needed to make sure all groups had access to the tablet when they wanted to start filming.

Software breakdowns were more recurrent in participant stories. Almost all participants (seven out of eight) provided examples of specific moments in the session, where they did not manage to enact their plans because of software breakdowns. For example, P8, a biology teacher, could not access, or edit her plans in class, because the installed version on the classroom's computer does not open her files.

Teachers who used software tools less often still presented software breakdowns. Yet, these breakdowns were less frequent compared to teachers who tried and used more software tools to plan and enact their sessions. P5, an English teacher, reported on four different alternatives to plan an activity with interactive videos. In one activity, she used Edpuzzle ${ }^{4}$, an educational software that supports annotating videos, cutting video sections, and adding questions. The problem with Edpuzzle: "students need to open a new window, they go out of mooodle ${ }^{5}$ (the educational platform used in her institution)" (P5). In a similar activity, P5 used h5p, another interactive tool for teachers. While h5p is a moodle plugin, she needed to spend time in class explaining how students can access the different parts of the video, and how they could use the codes she generated ahead of time. A third option she used for this type of activities consisted of cutting the video using MovieMaker, and adding the questions on a MS Word document. She would play the video section, and follow with the questions. The fourth option she presented consisted of preparing the questions before the session, based on the video content. In class, she would play the video, and stop manually at the end of the first section, and ask the questions. As she presented this alternative, P5 said: "I am getting a mobile keyboard. It will be great for this type of activities. I will be able to stop the video without having to stay close to the computer".

\footnotetext{
${ }^{4}$ https://edpuzzle.com/

${ }^{5}$ https://moodle.org/
} 


\section{Implications for Design}

We believe teaching tools should account for the challenges teachers face as they transition from plans to action, and we propose specific guidelines to support this transition.

\subsection{Capturing the activity, as it happens}

Teachers used digital tools to keep traces of the activity after its end. While they managed to keep track of the structure and content they followed, they could not keep a trace of the changes they made to the plan, and of how they responded to unexpected events. These traces could help teachers better adapt to a specific student group, classroom, or content. They could also help teachers reflect on their practices, and improve them for upcoming years.

Pedagogical activity planning and enactment tools should support capturing content and instructions as they are enacted in class. Most teachers in our interviews added content, instructions, and changed their activity soon after the session. For example P3, a history teacher, mentioned: "I take notes on a sheet of paper. Then, I edit my plan in the evening. I do this the same day."

Capturing traces could take different forms. Teachers could take pictures, record audio, or create their own way of capturing traces they find important during the session. Tracing can also happen implicitly, as the teacher or students change the plan in class. Then, after the session, the teacher can compare the planned session, to what actually happened in class and improve the plan for future sessions.

\subsection{Externalizing and sharing plans}

All teachers in our interviews shared their plans with students before class. While the teacher and students pointed at several resources and in-class activities, they both came back to the plan, on regular basis, to track and regulate their progress. Teachers need a shared representation of the plan from where they can point to other content, questions and instructions. In this representation, the plan becomes a shared communication channel between the teacher and students. They both create, edit, and complement the plan as the session unfolds.

\subsection{Supporting richer cross-device interaction}

Several breakdowns occurred when teachers moved files from one device to another. This resulted in losing formatting, content, or wasting time. The multiplicity of applications and devices in teachers' practices raises interoperability problems planning and enactment tools should address. They should support teachers in organizing resources in the planing phase, and link these resources to the plan as it is enacted.

Several teachers emphasized issues related to limited storage space and network speed. Planning and enactment tools should be designed around the storage and network constraints of the classroom environment. 


\section{Conclusions and Future Work}

In this paper, we investigate ways in which teachers manage the transition between the plans they design before class, and the activity as it unfolds in class with students. Our primary focus is on current tool use, and how it can inspire the design of novel tools to support teachers in transitioning from plans to action.

We conducted contextual interviews with middle and high school teachers, and found that most plans are created using digital tools. We identified breakdowns and bright spots in current teachers' practices before and during the session. We found that most breakdowns occurred when teachers used digital tools before and during the session. Our findings confirmed several initial hypotheses on unexpected events during class. These unexpected events make the transition from plans to action complex for teachers. For example, network and hardware issues were recurrent in participant stories, and often created problems with document transfer across different devices. We found that teachers create planning strategies to work around these problems. For example, they include lightweight versions of the content they want to use in their plans. They make sure the content is accessible in class, while still positioning it correctly in the session structure.

Xhakaj et al. also conducted contextual interviews with teachers to investigate how they collect data about students [24]. Our approach focuses on how teachers tool use affects their planning and enactment practices over time. We look at current breakdowns, but also analyze situations in which teachers succeeded in enacting their plans, and how their strategies in these situations could inspire the design of novel tools to support them in the transition between pedagogical plans and action.

In addition to the empirical work we present in this paper, we are building prototypes to demonstrate our design implications. We are currently running co-design sessions with teachers, and working together to investigate how to

best integrate prototypes in their current practices in planning and enacting pedagogical activities.

\section{References}

1. Akrich, M.: Comment décrire les objets techniques? Techniques et culture (9), 49-64 (1987)

2. Braun, V., Clarke, V.: Using thematic analysis in psychology. Qualitative research in psychology $3(2), 77-101$ (2006)

3. Dalland, C.P., Klette, K.: Individual teaching methods: Work plans as a tool for promoting self-regulated learning in lower secondary classrooms. Education Inquiry 7(4), 28249 (2016)

4. Dillenbourg, P.: Trends in orchestration. Second research \& technology scouting report. Tech. rep. (2011)

5. Dillenbourg, P.: Design for Classroom Orchestration. Comput. Educ. 69, 485-492 (Nov 2013)

6. Dillenbourg, P., Hong, F.: The mechanics of CSCL macro scripts. International Journal of Computer-Supported Collaborative Learning 3(1), 5-23 (2008) 
7. Dillenbourg, P., Jermann, P.: Designing Integrative Scripts. In: Fischer, F., Kollar, I., Mandl, H., Haake, J.M. (eds.) Scripting Computer-Supported Collaborative Learning, vol. 6, pp. 275-301. Springer US, Boston, MA (2007)

8. Dillenbourg, P., Zufferey, G., Alavi, H.S., Jermann, P., Do, L.H.S., Bonnard, Q., Cuendet, S., Kaplan, F.: Classroom orchestration : The third circle of usability. In: Connecting CSCL to Policy and Practice: CSCL Conference Proceedings. Volume I - Long Papers. vol. 1, pp. 510-517. Hong Kong, China (2011)

9. Dimitriadis, Y., Prieto, L.P., Asensio-Pérez, J.I.: The role of design and enactment patterns in orchestration: Helping to integrate technology in blended classroom ecosystems. Computers \& Education 69, 496-499 (2013)

10. Doré, S., Basque, J.: Le concept d'environnement d'apprentissage informatisé. International Journal of E-Learning \& Distance Education 13(1), 40-56 (2007)

11. Fong, C., Cober, R.M., Moher, T., Slotta, J.D.: The 3r orchestration cycle: fostering multi-modal inquiry discourse in a scaffolded inquiry environment. In: Proceedings from the Annual meeting CSCL Conferenece (2015)

12. Jalal, G., Maudet, N., Mackay, W.E.: Color portraits: From color picking to interacting with color. In: Proceedings of the 33rd Conference on Human Factors in Computing Systems. pp. 4207-4216. ACM CHI'15, ACM, New York, USA (2015)

13. Kali, Y., McKenney, S., Sagy, O.: Teachers as designers of technology enhanced learning. Instructional Science 43(2), 173-179 (Mar 2015), http://link.springer.com/10.1007/s11251-014-9343-4

14. Kobbe, L.: Framework on multiple goal dimensions for computer-supported scripts, kaleidoscope, d21. 2.1 (2006)

15. Looi, C.K., Song, Y.: Orchestration in a networked classroom: Where the teacher's real-time enactment matters. Computers \& Education 69, 510 - 513 (2013)

16. Paquette, G., Léonard, M., et al.: Modèles et métadonnées pour les scénarios pédagogiques (2013)

17. Rodríguez-Triana, M.J., Martínez-Monés, A., Asensio-Pérez, J.I., Dimitriadis, Y.: Scripting and monitoring meet each other: Aligning learning analytics and learning design to support teachers in orchestrating CSCL situations. British Journal of Educational Technology 46(2), 330-343 (Mar 2015)

18. Roschelle, J., Dimitriadis, Y., Hoppe, U.: Classroom orchestration: synthesis. Computers \& Education 69, 523-526 (2013)

19. Sharples, M., Scanlon, E., Paxton, M., Kerawalla, L., Feisst, M., Gaved, M., Wright, M., Collins, T., Anastopoulou, S., Mulholland, P.: nQuire: Technological Support for Personal Inquiry Learning. IEEE Transactions on Learning Technologies 5, 157-169 (2012)

20. Sharples, M.: Shared orchestration within and beyond the classroom. Computers \& Education 69, 504-506 (2013)

21. Streibel, M.J.: Instructional plans and situated learning: The challenge of suchman's theory of situated action for instructional designers and instructional systems. Journal of Visual Literacy 9(2), 8-34 (1989)

22. Suchman, L.A.: Human-machine reconfigurations: plans and situated actions. Cambridge University Press (2007)

23. Tchounikine, P.: Clarifying design for orchestration: orchestration and orchestrable technology, scripting and conducting. Computers \& Education 69, 500-503 (2013)

24. Xhakaj, F., Aleven, V., McLaren, B.M.: How teachers use data to help students learn: Contextual inquiry for the design of a dashboard. In: Verbert, K., Sharples, M., Klobučar, T. (eds.) Adaptive and Adaptable Learning. pp. 340-354. Springer International Publishing, Cham (2016) 